Research Article

Kang Yang*, Yi-lin Guo, Dong-hui Li, Gang Ma, Hao Geng, Qun-fang Li, and Ji-jia Xue

\title{
Design and static testing of wing structure of a composite four-seater electric aircraft
}

https://doi.org/10.1515/secm-2020-0023

Received Apr 04, 2020; accepted Jun 17, 2020

\begin{abstract}
Because of its light weight, high strength, designable, composite materials are more and more widely used in the field of aerospace, especially in the field of general aviation. In this paper, the structural design and analysis of the composite wing (include wing beam, rib, skin, leading edge and trailing edge) of a four-seater electric aircraft were carried out. The finite element numerical analysis model of the composite wing was established, and the deformation and strain distribution of the composite wing under the limited load required by airworthiness regulations were calculated. Finally, the static test of the whole composite wing was carried out to verify the accuracy of the finite element results. The finite element analysis and testing results showed that the structural design of the composite wing of the electric aircraft meets the structural strength requirements specified in the airworthiness standard (part 23 of China civil aviation regulations: airworthiness requirements for normal, practical, special effects and commuting aircraft: CCAR 23-R3)
\end{abstract}

Keywords: Four-seater electric aircraft; Composite wing; Static testing; Finite element analysis; CCAR 23-R3

\footnotetext{
`Corresponding Author: Kang Yang: Design department, Liaoning General Aviation Academy, Shenyang 110136; Liaoning Key Laboratory of General Aviation, Shenyang Aerospace University, Shenyang 110136; Email: ykangok@163.com

Hao Geng: Design department, Liaoning General Aviation Academy, Shenyang 110136; Email: genghao@lgaa.com.cn

Yi-lin Guo, Dong-hui Li, Gang Ma, Qun-fang Li: Design department, Liaoning General Aviation Academy, Shenyang 110136; Liaoning Key Laboratory of General Aviation, Shenyang Aerospace University, Shenyang 110136

Ji-jia Xue: Design department, Liaoning General Aviation Academy,Shenyang 110136; Liaoning Rui-xiang General Aircraft Manufacturing Co., LTD, Shenyang 110136
} ¿ Open Access. () 2020 K. Yang et al., published by De Gruyter. (cc) BY License

\section{Introduction}

In recent years, Europe and other developed countries are calling for improving the environmental protection performance of aircraft and building green aviation. Many institutions are working to alleviate the impact of aviation on the environment. The emergence of new energy electric aircraft provides a bright technical way for the thorough greening of aviation [1-8]. In addition, because of the more and more extensive application of composite materials in the field of aviation [1-8], the design and manufacture of light-weight and high-strength composite structures has become one of the challenges faced by the development of electric aircraft [1]. Yang Ket al. [12] conducted finite element analysis and static testing on composite wing of a two-seater electric aircraft. The stress distribution at the reference point and the wing tip deformation obtained from the testing and analysis results were in good agreement. At the same time, it was verified that the composite wing structure meets the requirements for aircraft structure strength in ASTM F2245-11 [13]. Du Chunzhi et al. [14] designed the composite structure of the wing of a lowspeed aircraft in the way of layering and geometric modeling, and analyzed the strength and stiffness of the wing in different layering by ANSYS finite element software. The results showed that the composite wing had lighter weight, higher strength and greater stiffness than the traditional wing under the same working condition. Wang Tong and Wu Zhen [15] based on the wing model of aircraft which named $\mathrm{x}$, established the wing model of half composite, all composite and all metal with the method of equal rigidity design, and carried out the finite element analysis under the same aerodynamic shape and load with ABAQUS software. The analysis results showed that the weight of half composite wing was about $35 \%$ less than that of all metal wing, and the weight of all composite wing was nearly $50 \%$ less than that of all metal wing. Smith, H. W. [16] studied the structural design, the static testing equipment and the testing method of hydrogen fuel light UAV. The test results were in good agreement with the previous analysis results. In order to meet the requirements of long-life, Zhang W et al. [17] carried out lightweight design for the 
structure of small ultra light solar UAV according to the mechanical characteristics of the structure, and the rationality of the structure was verified by the finite element analysis and static testing method. Finally, the finite element modal analysis was carried out, and then the finite element analysis results were modified according to the modal testing results. The agreement obtained was very good between the experimental results and the theoretical predictions. Simsiriwong $j[18]$ has studied the static and vibration characteristics of the wing and fuselage structure of a full-size carbon fiber composite of the ultra light UAV, and designed a hydraulic system and a tail fixing device, obtained the static response, natural frequency, damping coefficient and vibration mode of the two structures under the simulated load. In the above research and other available literature, there were no research about the composite wing structure design and analysis of a fourseat electric aircraft.

In this paper, the structural design method of the composite wing of a four-seater electric aircraft was studied. Then, the structural model of the wing was numerically simulated by the finite element analysis software. Finally, the static testing and analysis results of the full-size composite wing were compared to verify whether the wing structure meets the CCAR 23-R3 [19] airworthiness clause, which showed the rationality of the wing structure design, and provided a certain reference for relevant researchers to carry out the structural design of the same level of aircraft.

\section{Structural design of the composite wing}

\subsection{The structure and connection of wing}

The overall dimensions and structural of the aircraft and wing were shown in Figure 1 and Figure 2. The span was $13500 \mathrm{~mm}$ (the flap span was $3650 \mathrm{~mm}$, the aileron span was $2000 \mathrm{~mm}$ ), the maximum take-off weight was $1200 \mathrm{Kg}$, and the maximum overload was $+3.8 \mathrm{~g} /-1.52 \mathrm{~g}$. The wing consisted of main wing, flap and aileron. The main wing was single beam structure, and the wing beam was I-beam structure of cross section, which was located at the maximum thickness of the wing (about 30\% chord length).

The wing and fuselage were connected by pins, which were fixed by four rib pins to transfer the wing shear and torque to the fuselage. The left and right wing beams were connected by two wing beam butt pins to realize the moment self-balance of the wing, as shown in Figure 3.

\subsection{The materials and ply design of the wing}

The wing was made of carbon fiber/glass fiber composite (manufacturer was Weihai Guang-wei composite material Co., Ltd.) and foam sandwich structure, materials and brand name: $3 \mathrm{~K}$ carbon cloth (W-3021FF), carbon fiber unidirectional prepreg (UIN 23100), glass fiber cloth (SW110c100a) and foam (H60 4 PSC). The mechanical properties of each material were shown in Table 1. The main parts of the wing (include skin, root rib, flange strip of wing beam, web, front/rear edge of wing) used hand lay-up method and were laid shown in Table 2.

\section{Finite element analysis and wing static testing}

\subsection{Finite element analysis model}

In the finite element analysis, HyperMesh software was used for mesh generation, boundary condition setting, other pre-processing and post-processing. Nx.nastran software was used for calculation. The finite element model used the triangle/quadrilateral shell, and the connection of the pin used the MPCs (a contact algorithm for shell) to associate the two components. The boundary constraint points were the root rib pin and the wing beam butt pin. The numbers of element were 86360 and the numbers of node were 192664, and the finite element model shown in Figure 7.

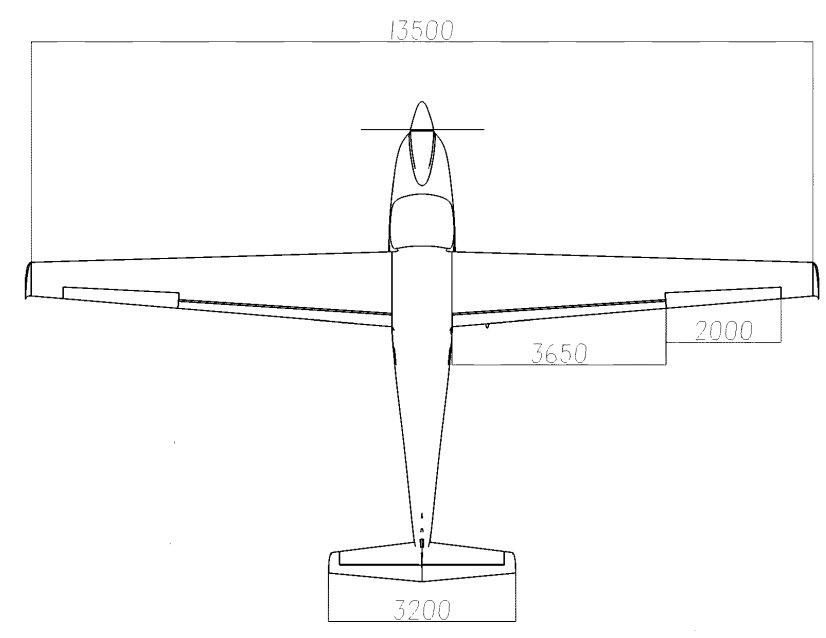

Figure 1: Outline dimension diagram of aircraft $(/ \mathrm{mm})$ 
Table 1: Mechanical property of materials

\begin{tabular}{ccccc}
\hline mechanical properties & W-3021FF & SW110c-100a & UIN 23100 & H604PSC \\
\hline$E_{11} / \mathrm{GPa}$ & 59.0 & 26.8 & 136.0 & 0.0012 \\
$E_{22} / \mathrm{GPa}$ & 59.0 & 26.8 & 0.037 & - \\
$G_{12} / \mathrm{GPa}$ & 9.5 & 7.3 & 0.037 & - \\
$V_{12}$ & 0.062 & 0.126 & 0.33 & 0.32 \\
\hline
\end{tabular}

Table 2: Layout of wing main structure

\begin{tabular}{ccc}
\hline the main parts & quantity & orientation \\
\hline skin & 14 & $\mathrm{~s} 45 /[\mathrm{t} 0] 3 / \mathrm{p} / \mathrm{t} 0 / \mathrm{s} 0$ \\
front edge & 4 & {$[\mathrm{t} 0] 2$} \\
rear edge & 8 & $\mathrm{t} 0 /[\mathrm{t} 45] 2 / \mathrm{t} 0$ \\
root rib & 28 & {$[\mathrm{t} 0 / \mathrm{t} 45] 2 /[\mathrm{t} 0] 10 /[\mathrm{t} 0 / \mathrm{t} 45] 2$} \\
flange strip & 40 & {$[\mathrm{u} 45] /[\mathrm{u}(-45)] /[\mathrm{u} 0] 29 /[\mathrm{u}(-45)] /[\mathrm{u} 45]$} \\
web & 44 & {$[\mathrm{t} 0] 8 /[\mathrm{p} 4] 2 /[\mathrm{t} 0] 20 /[\mathrm{t} 45] 13 / \mathrm{p}$} \\
\hline
\end{tabular}

Note: 45 indicated that the woven fabric was in $\pm 45^{\circ}$ orientation. 0 indicated the $0^{\circ} / 90^{\circ}$ orientation of the woven fabric. $\mathrm{s}$ indicated the glass fiber cloth. $t$ indicated $3 \mathrm{~K}$ carbon cloth. $\mathrm{u}$ represents carbon fiber unidirectional prepreg. $\mathrm{P}$ represent foam.

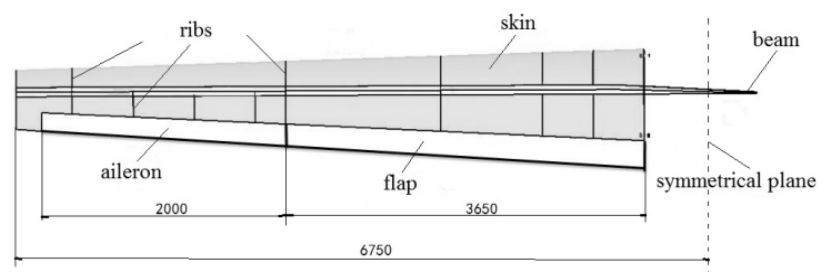

Figure 2: The wing structure $(/ \mathrm{mm})$

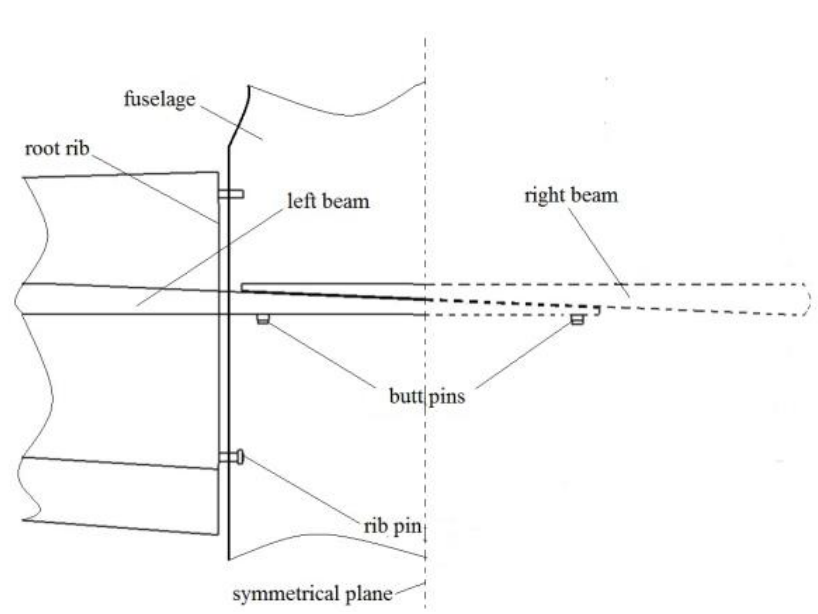

Figure 3: Schematic diagram of wing-fuselage connection

\subsection{Static testing of the wing}

The static test of the wing was carried out by the combination of the clamp pallet and the lever system. The levers were divided into three levels. The restraint points of the test piece were the root rib pins and the wing beam butt

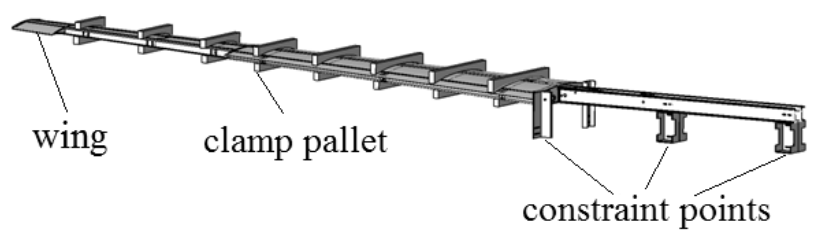

(a)

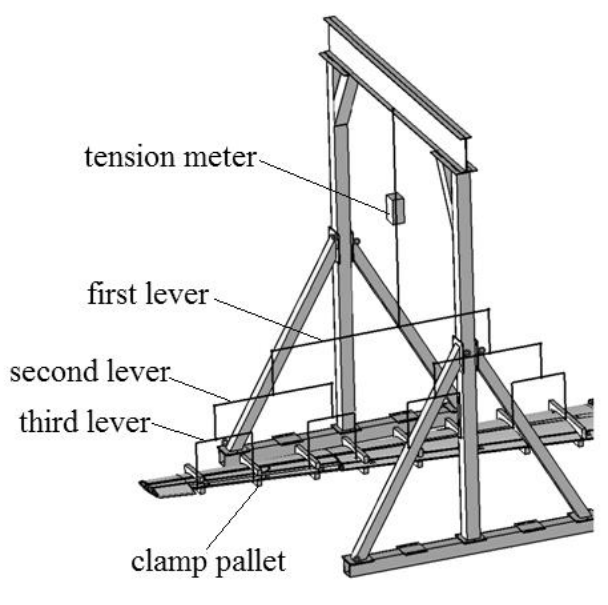

(b)

Figure 4: The loading system of wing

pins, as shown in Figure 4(a). The loading equipment was electric portal jib crane, and tension was monitored by tension meter, as shown in Figure 4(b).

The wing was divided into 8 regions from the wing root to the wing tip, and the boundary of each region was between the two adjacent pallets. According to the principle 
Table 3: Position and limit loads of wing clamp

\begin{tabular}{ccc}
\hline NO. & Distance from wing root/mm & The limit load/N \\
\hline L1 & 501 & 2552 \\
L2 & 1215 & 1955.8 \\
L3 & 1925 & 2171 \\
L4 & 2635 & 1916.6 \\
L5 & 3349 & 1554 \\
L6 & 3993 & 1454 \\
L7 & 4753 & 1042.5 \\
L8 & 5513 & 1954 \\
\hline
\end{tabular}

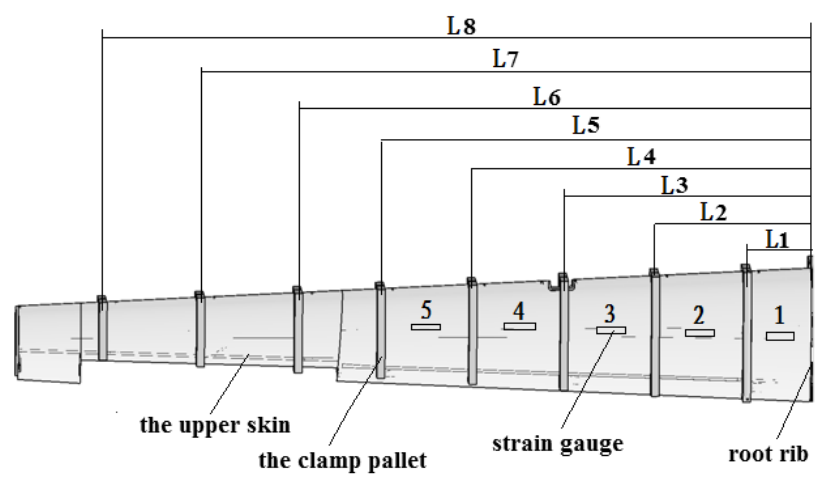

Figure 5: Position of strain gauge

of equivalent shear force and bending moment, all aerodynamic forces and inertia forces in this area were combined. Similarly, the location of each loading point in chord direction was determined according to the principle of equivalent shear force and bending moment.

According to the requirements of relevant provisions of CCAR 23-R3: for normal, practical and commuter aircrafts, symmetrical wing load test under the case A (in the flight envelope of the aircraft, the limited maneuvering load point of the aircraft) was required. In Table 3 and Figure 5, the location and load of the clamp pallets were shown. Due to the symmetrical loading of the left and right wings, so the left wing was selected for loading test, and loaded to the limit load which was $67 \%$ of the ultimate load.

\subsection{Testing project and equipments}

Static testing measurement data included tip deformation and strain at reference point of the wing. The deformation of wing tip was recorded by placing a steel scale. For the strain measurement, pasted the strain gauge symmetrically on the upper/lower skin of the left wing at the middle between the clamp pallet, and between the clamp pal- let and the root rib, along the direction of the main wing beam, as shown in Figure 5. Moreover, the strain collection system used Donghua-DH3820 high-speed strain gauge which made in China, the strain gauge model was BF3505AA(11)N6-X and produced by CETCA. And all the above equipments were qualified after verification.

\section{The static testing and finite element analysis results}

After the testing was loaded to the limit load and kept for 30s shown in Figure 6. There were no abnormal sound and damage on the wing. At this time, the deformation of the wing tip was $772 \mathrm{~mm}$. And after unloading, the deformation of the wing tip was $16 \mathrm{~mm}$ relative to the initial state. The preliminary analysis was caused by the assembly clearance of each component. The deformation was small and the wing does not have plastic deformation. Therefore, the strength of the wing structure met the requirements of CCAR 23-R3 airworthiness clause (clause 23.305 stipulates that the structure must be able to bear the limited load without harmful permanent deformation and under any load until the limited load, the deformation will not affect the safe operation).

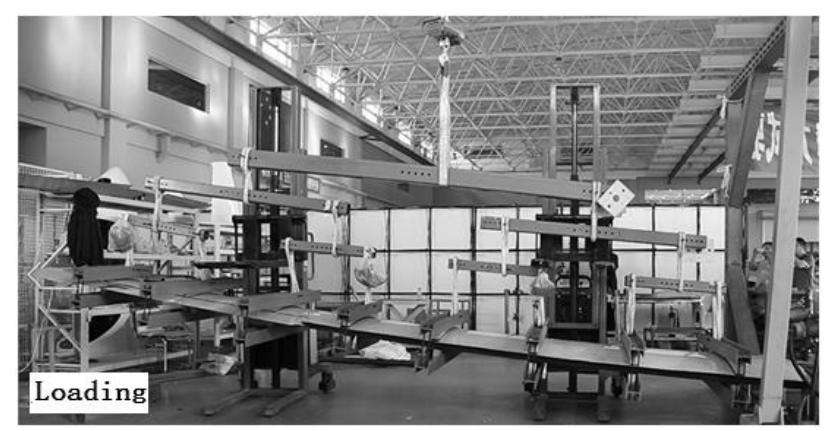

(a)

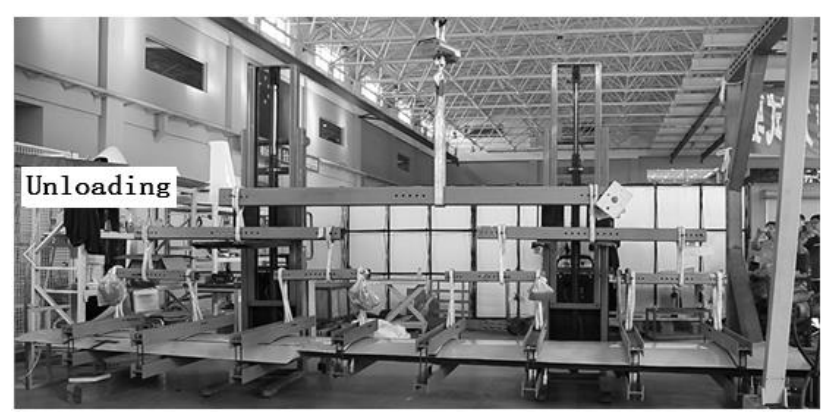

(b)

Figure 6: The result of static testing 


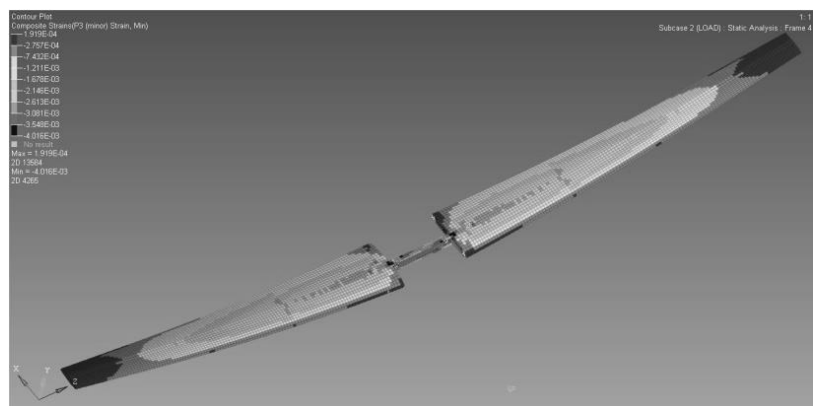

(a)

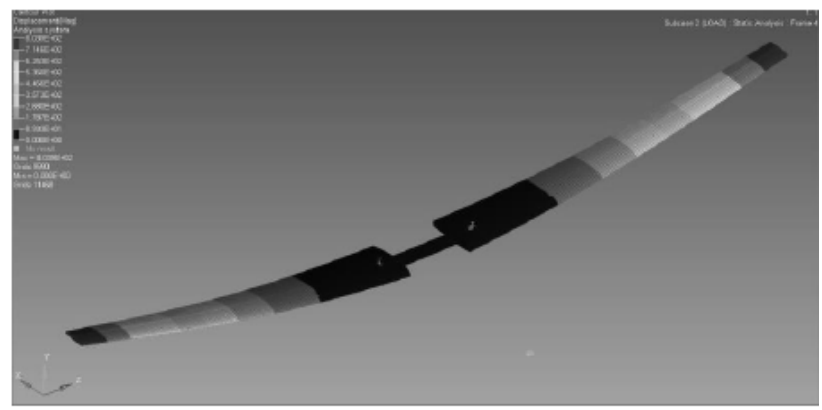

(b)

Figure 7: The result of finite element (FE) analysis, (a) is the strain distribution nephogram, (b) is the deformation distribution nephogram

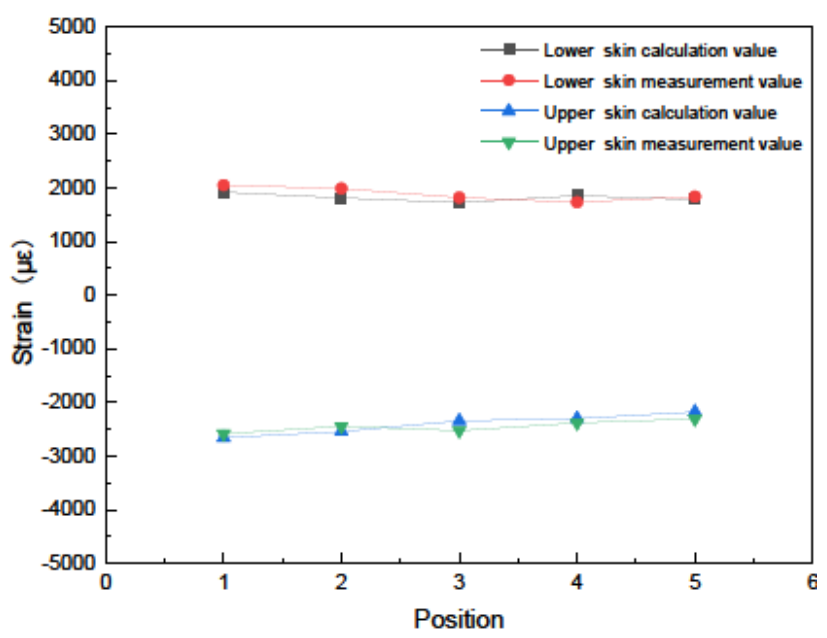

Figure 8: The result of strain measurement and FE analysis

For the strain measurement results, the maximum value of the upper wing skin was $-2586 \mu \varepsilon$, and the lower wing skin was $2047 \mu \varepsilon$. According to the testing results and the finite element analysis results shown in Figures from 6 to 8 , the maximum deformation calculation value of wing tip was $803 \mathrm{~mm}$, the maximum calculation value of upper wing skin strain was $-2730 \mu \varepsilon$, and the maximum calculation value of lower wing skin was $1919 \mu \varepsilon$. The difference
Table 4: The deformation of measurement and FE analysis to the left wing tip

\begin{tabular}{cc}
\hline Results & The deformation of wing tip $/ \mathrm{mm}$ \\
\hline measurement & 772 \\
FE analysis & 803 \\
relative error & $4.0 \%$ \\
\hline
\end{tabular}

between the finite element analysis and the testing value was small. The wing tip deformation was shown in Table 4, so the strain measurement value and the wing tip deformation testing result were in good agreement with the corresponding finite element analysis calculation value. Therefore, the results of finite element analysis were accurate and reliable.

\section{Conclusion}

In this paper, the finite element method was used to analyze whether the structural design of the composite wing of a four-seater electric aircraft can meet the strength requirements of airworthiness regulations under limit load. The results were verified by full-scale wing static testing and the conclusions were as follows:

(1) The force transfer route between wing and fuselage met the requirements of the aircraft structural strength.

(2) Under the limit load, the wing structure had no plastic deformation and damage, and the structural strength met the requirements of CCAR 23-R3 airworthiness regulations for normal, practical, special and commuter aircraft.

(3) The results of the finite element analysis were in good agreement with the experimental results, which proved the applicability of the finite element analysis results.

(4) The connection design of wing and fuselage had certain reference significance for relevant structural designers.

\section{References}

[1] HUANG Jun, YANG Fengtian. Development and challenges of electric aircraft with new energies. Acta Aeronautica et Astronautica Sinica. 2015; 37(1):57-68.

[2] LIN Z M. Making aviation green. Advance in Manufacturing. 2013; 1:42-49. 
[3] HYDER A K. A century of aerospace electrical power technology. Journal of propulsion and power. 2003; 19(6):1155-1179.

[4] STEINER H, VRATNY P C, GOLOGANC, et al. Optimum number of engines for transport aircraft employing electrically powered distributed propulsion. CEAS Aeronautical Journal. 2015; 5(2):157170.

[5] SALANM A, EUNUS Z I. Recent green aviation technologies an overview. Journal of Modern Science and Technology. 2013; 1(1):61-75.

[6] TOMAZIZ T, PLEVNIK V, VEBLE G, et al. Pipistrel Taurus G4: On creation and evolution of the winning aero-plane of NASA green flight challenge 2011.Journal of Mechanical Engineering. 2011; 57(12):869-878.

[7] BRUCE P G,FREUNBERGER S A,HARDWICK I J, et al. LiO2 and LIS batteries with high energy storage. Nature Materials. 2012; 11(1):19-29.

[8] SRILATHA A R. Design of a 4-seat general aviation electric aircraft. San Jose: San Jose State University; 2012.

[9] Tang Jianmao. Review of studies of carbon fiber resin matrix composites. SPACECRAFT ENVIRONMENT ENGINEERING. 2010; 27(3): 269-280.

[10] Zhang Xianhua, Gao Yanqiu, et al. Development and applications of carbon nanotubes and continuous carbon fiber reinforced composites. Aeronautical Manufacturing Technology. 2014; 459(15):71-73.
[11] BAO Jianwen, JIANG Shicai, ZHANG Daijun. Current status and trends of aeronautical resin matrix composites reinforced by carbon fiber. Science \& Technology Review. 2018; 36(19): 52-63.

[12] Kang Yang, Liguo Zhang, Shude Ji, Yumei Yue, Wang Ji. Static testing and analysis of composite wing of a two-seater aircraft powered by Li-ion battery electric propulsion. Advanced Composites Letters. 2016; 25(6):127-131.

[13] ASTM F2245-11, Standard Specification for Design and Performance of a Light Sport Airplane.

[14] DU Chunzhi, FU Boyu, QIU Zhihao. Design and finite element analysis of composite wing for a low speed aircraft. JOURNAL OF MACHINE DESIGN. 2019; 36(S2):55-58.

[15] Wang Tong, Wu Zhen. Finite element analysis for simulate composite wing of $X$ model aircraft. Journal of Shenyang Aerospace University. 2011; 28(05):48-51.

[16] SMITH, Howard W. Static test of an ultralight airplane. Journal of Aircraft. 1988; 25(1):37-40.

[17] Zhang W, Yao L J, Tong X Y. Structural Design and Testing of Small Ultralight Solar-Powered Unmanned Aerial Vehicle. Advanced Materials Research. 2011; 317-319:227-230.

[18] Simsiriwong J. Structural testing of an ultralight UAV composite wing and fuselage. Dissertations \& Theses Grad-works; 2009.

[19] CAAC. Part 23 of China civil aviation regulations: airworthiness requirements for normal, practical, special effects and commuting aircraft: CCAR 23-R3. Beijing: CAAC. 